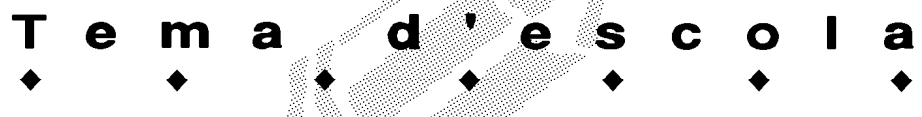

\section{LA MÚSICA ALS ESTUDIS DE MAGISTERI}

\author{
Joaquim Icart Garcia. Àrea de Música. URV
}

\section{Una ullada al passat més immediat}

Els antecedents musicals més propers als nostres dies, dins els estudis de Mestre, cal anar a cercar-los a la dècada dels anys 60, quan l'aleshores Escola Normal del Magisteri «Verge del Claustre» estava ubicada vora l'Amfitreatre Romà mirant de front al nostre mar. Uns antecedents que val la pena esmentar breument, no només per la nostàlgia de l'esperança juvenil allí viscuda per molts dels que segurament ara estan ocupant llocs de molta responsabilitat al món de l'educació, sinó com a fita històrica del passat comú per als futurs mestres.

Era el temps que tancava tota una època en què els alumnes encara assistien a les classes separats per sexes, després d'haver superat el batxillerat elemental als 14 anys, i el temps en què els nois no havien rebut la més mínima formació musical a l'escola elemental ni al batxillerat, ja que aquesta assignatura no figurava als programes educatius oficials. Així doncs, l'única formació musical que rebien la quasi totalitat dels futurs mestres era la que se'ls oferia a l'Escola Normal de Magisteri. Els estudis musicals als Conservatoris de Música eren aleshores cosa d'unes poques persones, molt poques en aquells temps de quasi postguerra.

Si bé els estudis de Magisteri havien seguit una tradició musical fortament arrelada al poble i la mantenien dins d'aquell desert cultural escolar, el seu estudi resultava, tot d'una, -encara que molt gratificant per a l'esperit- quelcom molt difícil d'exercitar per uns alumnes que no n'havien «après mai» a l'escola, ja que la capacitació musical no es pot assolir de cop i volta.

El Pla d'Estudis del 1967 significaria després un pas endavant important pel que fa al nivell de preparació inicial dels futurs mestres, ja que per a cursar aquell nou Pla eren necessaris uns estudis previs equivalents als demanats actualment per la Universitat. Tanmateix, la preparació musical dels alumnes patia inicialment dels mateixos mals esmentats abans, ja que ells també havien sofert els efectes d'aquella peculiar i crònica amúsia institucional.

Malgrat això, la incorporació a l'Escola com a catedràtic de Música del professor Pío Tur, gran concertista de piano i de valuoses inquietuds culturals, va significar, ja en aquell temps, una dignificació de la música com a disciplina universitària, no només com a professió i mitjà pedagògic de primer ordre, sinó com a eina de reflexió cultural i filosòfica del nostre entorn. La dedicació entusiasta dels alumnes, conscients que iniciaven una nova etapa plena d'esperança per al magisteri, va propiciar una intensa activitat musical que culminaria l'any 1972 amb l'edició per la discogràfica «Belter», i dirigida per l'esmentat professor, d'un disc amb cançons polifòniques interpretades pels alumnes de l'Escola Normal de Magisteri. Edició que va ser patrocinada per la Diputació de Tarragona, i que era ja el preludi del suport institucional que uns anys més tard protagonitzaria amb la col-laboració de molts ajuntaments de les nostres comarques per tal de fer possible la música a les escoles.

Cal remarcar que aquella va ser una experiència pionera a les Escoles de Magisteri i va voler ser l'exemple d'una nova manera d'entendre l'educació musical, en uns temps en què l'aprenentatge de mà dura i la discriminació dels alumnes per llurs capacitats o habilitats naturals encara eren costum generalitzat. Ningú va ser ni seleccionat ni exclòs per la seva millor o pitjor veu, ja que no es pretenia assolir un elevat nivell d'ensinistrament o de destresa professional, sinó un elevat nivell de sensibilitat espiritual i de convivència.

\section{La primera porta oberta a l'esperança}

Aquella fita coincidia amb la publicació un any abans (el 2 de desembre del 1970) de la «Ley General de Educación», que definia les normes i orientacions de la nova Educació General Bàsica, o EGB. Una llei que contemplava en principi, entre altres millores del currículum escolar, l'educació musical dels infants com a activitat d'obligat compliment dins l'horari escolar.

Una concessió que en principi venia a il-lusionar la creixent reivindicació social per l'educació musical dels infants, ja que l'esmentada llei contemplava almenys un minso $6 \%$ del temps escolar per a l'esmentada activitat, o sigui, 1,5 hores setmanals. Però, ai l'as! Entre les àrees d'expressió no hi constava la de música. L'exòtica activitat musical que es demanava per a la Primera Etapa, (dels 6 als 12 anys) estava inclosa dins l'Àrea d'Expressió Dinàmica, i a més, no era fins a la Segona Etapa, a partir dels 12 anys que la música no era contemplada de forma diferenciada a la «Educación Física y Deportes».

Però això no era tot, ja que si bé la llei contemplava l'activitat musical, tanmateix no s'havien creat les places 


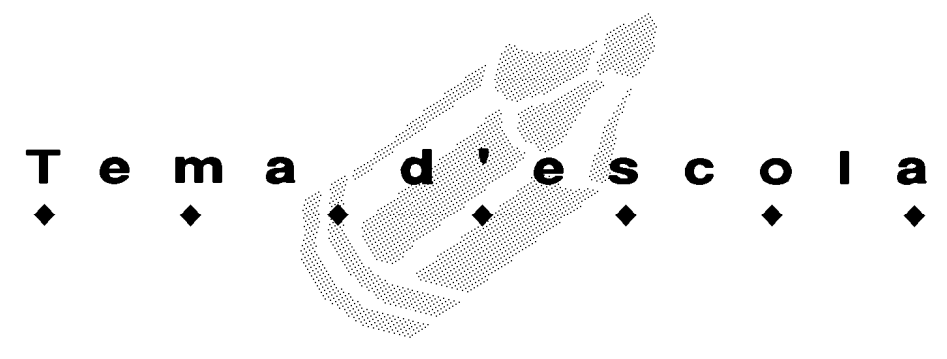

de Mestres Especialistes de Música per tal d'assumir amb eficàcia aquesta responsabilitat educativa. Era evident que la preparació dels mestres era del tot insuficient, exceptuant els casos en què la mestra o el mestre havien cursat, per compte propi, estudis musicals al Conservatori. Així, a la Segona Etapa de l'EGB només podien prendre la responsabilitat de l'educació musical aquells 0 aquelles poques mestres que havien «fet música en un Conservatori», i era evident que, com que una flor no fa estiu, el problema de la música a l'escola quedava totalment sense resoldre.

Dintre de tanta amúsia i improvisació per part de les Institucions Estatals, quedava l'esperança que els futurs plans d'estudis de Magisteri tindrien cura d'aquesta greu mancança. No va ser així tampoc, i al Pla d'Estudis del 1972, un Pla provisional destinat a durar 20 anys, no hi constava cap especialització en Educació Musical. Malgrat això, es va obrir una escletxa amb l'aparició als anys 80 de l'Especialitat de Pre-escolar, la qual contemplava una dedicació especial a la música de 2 hores setmanals anuals equivalents a 6 crèdits actuals. Solució esquifida que venia a corroborar una manca de plantejament seriós de l'educació musical a l'escola.

Així doncs, amb tota aquesta estreta previsió de futur, quedava totalment desvalguda l'educació musical a l'EGB, i com que la llei contemplava que: «En cada área, además de los profesores del centro, podrán colaborar especialistas de otros niveles de enseñanza, de organización y métodos, etc.», i a més a més no hi havia ni àrea de Música ni la corresponent especialitat, i només molt pocs i poques mestres que «sabessin realment música», la demanda social es va desbordar, i pertot arreu les Associacions de Pares d'Alumnes, també contemplades en l'esmentada llei, anaven reclamant, l'una rere l'altra, la música a l'escola.

\section{Per fi, la música a l'escola}

La tradició a Catalunya d'una escola activa es remunta a principis del $\mathrm{s}$. $\mathrm{XX}$, amb les primeres experiències d'un Alexandre Galí, o d'una $\mathrm{M}^{\mathrm{a}}$ Montessori, entre les més destacades, les quals contemplaven l'educació artística, - saber observar i saber escoltar- com a eines fonamentals en l'educació de l'infant a través del descobriment personal i de l'entorn. Pel que fa a la pedagogia musical, el mestre Joan Llongueras, deixeble d'Emile Jaques-Dalcroze, havia introduït a l'escola catalana el prestigiós mètode d'educació musical d'aquest gran pedagog i músic suís, aportant una quantitat molt important de cançons i danses destinades a despertar i educar l'expressió musical dels més petits.

Una tradició d'escola lliure catalana ofegada pels trasbalsos polítics de meitat de segle, però conservada per algunes il-lustres institucions pedagògiques, recobrava ara la memòria i la consciència col-lectiva. La tradició popular de les antigues escoles municipals recobrava nova vida, i amb ella l'activitat musical hi entrava amb nous aires de modernitat. Així, a Barcelona, el mestre i compositor Joan Guinjoan, recentment distingit per la nostra Universitat com a Dr. Honoris Causa, emprenia per a aquell Ajuntament una sèrie d'activitats musicals d'autèntica avantguarda per a l'educació dels infants, similars a les ja iniciades en altres països europeus.

Pel que fa a les nostres comarques, també van ser els ajuntaments els que van assumir, des del primer moment i de forma majoritària, el compromís social de l'educació musical a les escoles amb la valuosa col-laboració de la Diputació, com abans s'ha esmentat. Va ser aleshores quan el treball d'equip realitzat per un col-lectiu de música a l'entorn del pare Ireneu Segarra es va introduir a bastament a la majoria d'escoles catalanes, i omplí de moment aquell buit històric de 40 anys de durada.

Tanmateix, la majoria d'aquells músics no eren mestres, i per tant no podien exercir com a tals a les escoles. Així doncs, la seva participació en la tasca educativa dins l'horari escolar era una anomalia que calia esmenar. Malgrat aquest inconvenient, les persones més preparades van cursar tot seguit els estudis de magisteri, i salvaren així l'obstacle acadèmic i administratiu que els barrava el pas a una plena incorporació a l'escola, demostrant així una autèntica vocació i una responsabilitat social admirables.

No va ser, però, fins a finals de la dècada dels 80 que es van organitzar els primers Cursos de Postgrau per tal d'homologar el títol de mestre en especialista en Educació Musical. Eren cursos destinats a mestres de carrera, els quals podien optar, per primera vegada en moltes dècades, a l'especialitat de Música.

Amb els antecedents abans esmentats de responsabilitat social envers la música, quan l'any 1990, en aplicació de la LOGSE es van iniciar els tràmits administratius necessaris per a la concessió, per part del Ministerio de Educación i Ciencia, de l'especialitat d'Educació Musical a l'Escola de Mestres, ens va ser planera i gratificant, sobretot la seva justificació social, ja que eren moltes les escoles de les nostres contrades on l'activitat musical havia esdevingut un fet escolar i social rellevant. En aquest punt, cal un agraïment a la Diputació Provincial i als ajuntaments de Reus i Tarragona per l'interès que van mostrar per donar-nos un informe complet sobre la important tasca d'educació musical que havien assumit, durant una llarga dècada de reconeixement i de compromís, amb aquella demanda 


\section{T e m a d'e s c o l a}

popular. Començava així una nova etapa plena d'esperança per a la plena normalització de l'activitat musical a les escoles.

\section{L'especialitat de música}

L'especialitat de Música en la formació de mestres va iniciar el seu camí coincidint amb la creació de la Universitat Rovira i Virgili, deixant enrere la Divisió VII de la Universitat de Barcelona i la incorporació de l'històric Magisteri a la Facultat de Ciències de l'Educació $\mathrm{i}$ Psicologia.

Tampoc no va ser fàcil el començament d'aquesta especialitat. I així, complint-se una vegada més el desconeixement que normalment hom té de les necessitats musicals, es va haver de muntar aquesta especialitat amb els únics recursos de què es disposava en aquell moment, i que era el fruit d'un esforç continuat de molts d'anys d'adquisició de material musical per part dels minsos pressupostos de què havia disposat l'àrea de Música.
Pel que fa al professorat, era en un principi el mateix que el que tenia la Universitat per a la formació musical abans de l'especialitat d'Educació Musical: les professores Isabel Sans i Montserrat Ríos i el professor Joaquim Icart, ja que l'anterior catedràtic, el Dr. Pío Tur, s'havia incorporat a la Universitat de Palma de Mallorca després d'haver estat conseller d'aquell Govern Balear durant tota una legislatura, i després de quasi 30 anys com a pedagog musical a l'Escola de Magisteri de Tarragona, durant els quals va deixar una vertadera escola de pedagogia musical de la qual som deutors els qui ara hem agafat les regnes de la tasca per ell iniciada.

Aquest fet va deixar sense cap professor titular l'àrea de Música, fins que un any després el professor Joaquim Icart va prendre possessió de la càtedra de Música i la professora Montserrat Ríos, la titularitat. Aquest esforç, però, no va ser obstacle perquè la professora Ríos, amb una preparació superior en Direcció musical, iniciés els primers assaigs del que ara tots coneixem, i en gaudim amb orgull, com a coral de la

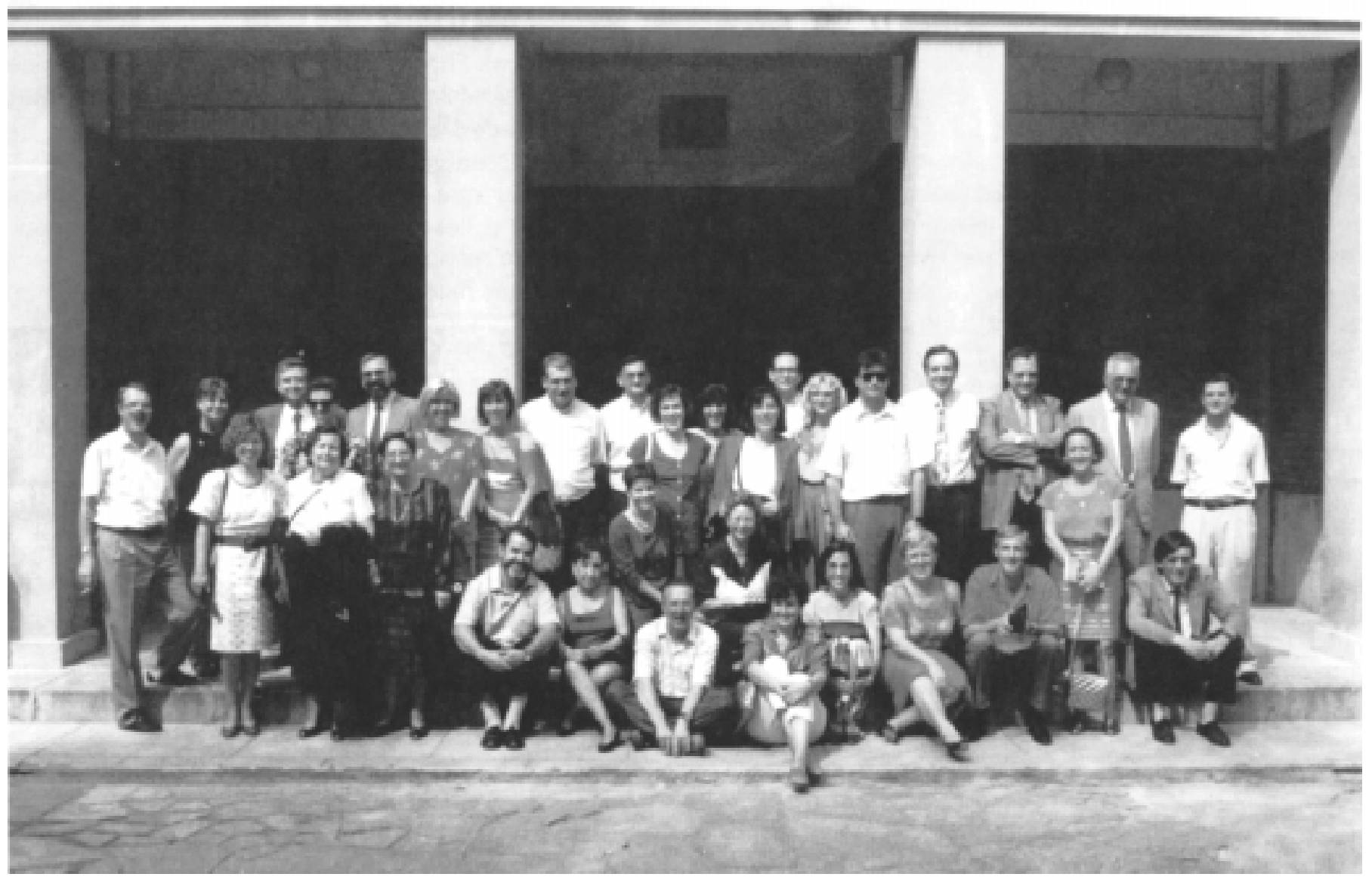

Primera promoció de mestres del pla del 1967, reunits a la port de l'antiga Escola Normal "Verge del Claustre", amb motiu de la cel-lebració del 25è anniversari de l'acabament dels estudis 


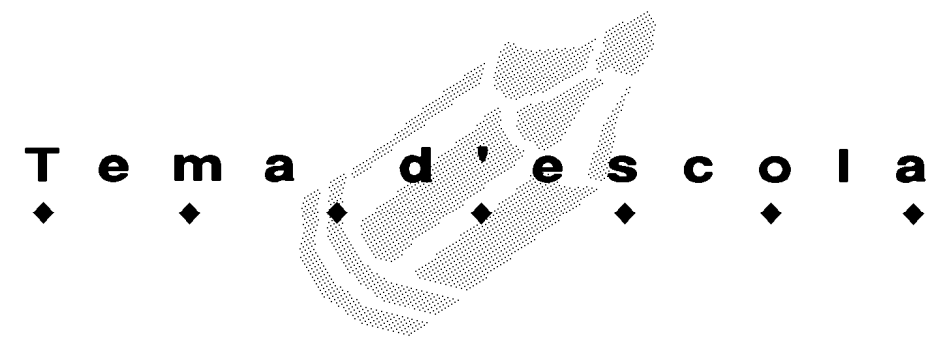

Universitat Rovira i Virgili.

Tres anys més tard, la professora Isabel Sans es jubilava també, després de 20 anys de docència exemplar. Persona d'una bondat natural, sempre per sobre del bé i del mal, havia contribuït igualment a mostrar una pedagogia profundament humanitzada.

La incorporació de la professora Enriqueta Barniol i posteriorment la del professor Agustí Bruach van significar un enorme enriquiment de l'equip de professors. La profesora Barniol com a gran experta en Didàctica de l'Expressió Musical i el professor Bruach, gran musicòleg, concertista i compositor, encara que posteriorment s'incorporaria a la Universitat de Ratisbona a Alemanya des d'on va ser cridat a impartir classes d'Anàlisi Musical, (precisament una de les assignatures optatives que havia impartit entre els nostres alumnes). Actualment, el professor Markus Schikora ha representat un nou impuls a les variades facetes de l'activitat musical aportant la seva gran experiència professional en els grans escenaris europeus com a concertista.

\section{El mestres especialistes en educació musical}

Tanmateix, un cop iniciat el pla d'estudis del 1992, va sortir a la llum un greuge comparatiu en contra dels alumnes que volien incorporar-se a aquesta especialitat, ja que només comptava per a la selecció d'ingrés la nota de selectivitat sense tenir-se cap consideració a la preparació musical prèvia. Aquest fet ha provocat situacions sorprenents, i així, mentre alguns alumnes amb una bona preparació musical no podien matricular-se en aquesta especialitat, d'altres s'hi podien matricular sense cap coneixement musical previ. Aquest fet, al marge del trasbals personal que necessàriament provoca a posteriori a l'alumne afectat, ens ha de fer reflexionar sobre alguns aspectes fonamentals:

En primer lloc, i en això hi estaran segurament d'acord totes aquelles persones que a més d'estudis universitaris amb un nivell de llicenciatura o superior, hagin superat alhora, i amb èxit, una carrera superior de música, els estudis musicals equivalen, pel cap baix, a dues llicenciatures; tant pel que fa al temps de dedicació pràctica i estudi que exigeix diàriament, com per les gran dificultats que s'han de superar, tant pel que fa a l'extraordinària destresa i control psicomotor, com per la difícil capacitació interpretativa, i l'elevat esforç intel.lectual que exigeixen algunes de les seves matèries teòriques, i que ara no és el moment d'enumerar. En tot cas, la demostració d'aquestes afirmacions és el fet que són molt poques les persones que superen aquests estudis, sobretot si les comparem amb totes les que només perseveren els primers anys. Aquest abandó prematur de molts estudiants no té paral-lel amb cap altra carrera, ni tan sols amb aquelles que es consideren més difícils de superar.

Si tenim en compte aquest fet, hom pot comprendre ben aviat el que això significa per al rendiment escolar de l'alumne que pren seriosament els estudis de música durant els estudis de Primària i de Batxillerat, i de la incomprensible i greu injustícia que rep després per part de la mateixa societat que l'ha fet créixer, quan ha d'esgrimir les notes de selectivitat per entrar a la Universitat.

Per aquest motiu, el qual creiem que és el més important per a l'alumne com a persona amb una sensibilitat artística, els alumnes de música haurien de restar les seves hores d'estudi musical d'altres de molt discutibles del currículum escolar; o bé, (i és això el que passa només als qui, tenint un talent privilegiat, una extraordinària capacitat de treball i una autèntica vocació musical, s'aventuren a una experiència com aquesta) han d'afegir moltes hores a les dedicades als estudis de Primària o Batxillerat; i a això se'n diu penar d'una forma totalment injusta el seu treball musical, sobretot, tal com ja s'ha esmentat, quan han d'esgrimir les notes de selectivitat com a resultat dels seus esforços.

En segon lloc, cal pensar que en una especialització universitària no és, ni molt menys el lloc on s'aprenen les primeres nocions d'aquella matèria. Així, a ningú li passarà pel cap estudiar veterinària sense diferenciar un gos d'un gat, o d'especialitzar-se en traumatologia sense diferenciar el cap dels peus.

En tercer lloc, i pel motiu abans esmentat de la quantitat d'hores requerides, del talent, capacitat de treball i autèntica vocació, que són necessaris per a una bona formació musical, l'escola no és el lloc més adequat per a aquest tipus d'exercitació tan intensa com difícil.

Potser és el moment de començar a entendre entre tots que la capacitació per a poder gaudir de la cultura, sigui aquesta musical o de qualsevol altre camp de l'art, no és gens fàcil i requereix un gran esforç personal. Aquesta capacitat s'assoleix en el decurs de la vida, i sobretot amb la cura personal que hom tingui de si mateix en aquest aspecte. Iniciar, doncs, aquest camí, no vol dir aprendre quatre regles o quatre símbols, sinó iniciar un meravellós i alhora llarg i difícil camí de reflexió estètica.

Obrir aquest camí i iniciar a caminar per ell als més petits és el propi de l'escola. Estar disposat a salvar els seus esculls i fer l'esforç que requereix la seva travessia és cosa d'aquelles i d'aquells que realment són capaços de descobrir les seves meravelles i de fer l'esforç necessari per arribar al cim on ens porta; i això últim 


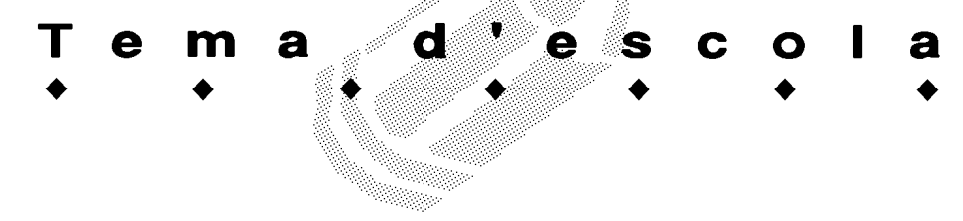

requereix un espai i un entorn adequat, de la mateixa manera que un científic no treballa amb el microscopi que li van regalar de petit. En tot cas, aquell microscopi li va obrir la curiositat, i probablement la vocació futura.

Per aquest motiu, si realment volem normalitzar els estudis musicals, com a mostra del més elemental respecte a la personalitat de totes aquelles nenes i nens que per la seva sensibilitat artística s'aboquen a la fascinant i difícil aventura artística, hauríem de permetre currículums artístics, on els més petits i els joves que ho desitgin puguin gaudir de l'educació que es mereixen, ja siguin aquests musicals, de belles arts, o dramàtics. En cas contrari, estem penant de forma greu la formació artística de la joventut i la cultura en general d'aquest país. Si realment volem normalitzar un país, comencem per acceptar com a normal un fet social evident i creixent, i respectar en conseqüència els delicats i elevats sentiments dels que inicien la seva vida. Segur que faríem una societat molt millor.
Cal deixar ben clar, doncs, que a l'especialitat de Mestre en Educació Musical no és el lloc on s'ensenyen quatre coses elementals perquè les puguin ensenyar després a l'escola, (si és que realment això és possible musicalment parlant). En tot cas, cap pedagog defensaria actualment aquest criteri educatiu.

Així doncs, l'ensenyament de mestre especialista en Educació Musical és el lloc on una desitjable excel-lent formació musical inicial dels alumnes es posa a prova per a la reflexió personal sobre l'aplicació de les seves conquestes prèvies, en l'educació de la sensibilitat musical dels més petits. Només en base a aquestes capacitats assolides individualment els alumnes poden entendre el sentit d'una adequada utilització dels recursos didàctics per tal d'aplicar-los a una bona educació de la sensibilitat musical amb el degut seny i bon gust. Aquest és el repte que assumim tots plegats, tant professors com alumnes de l'especialitat d'Educació Musical.

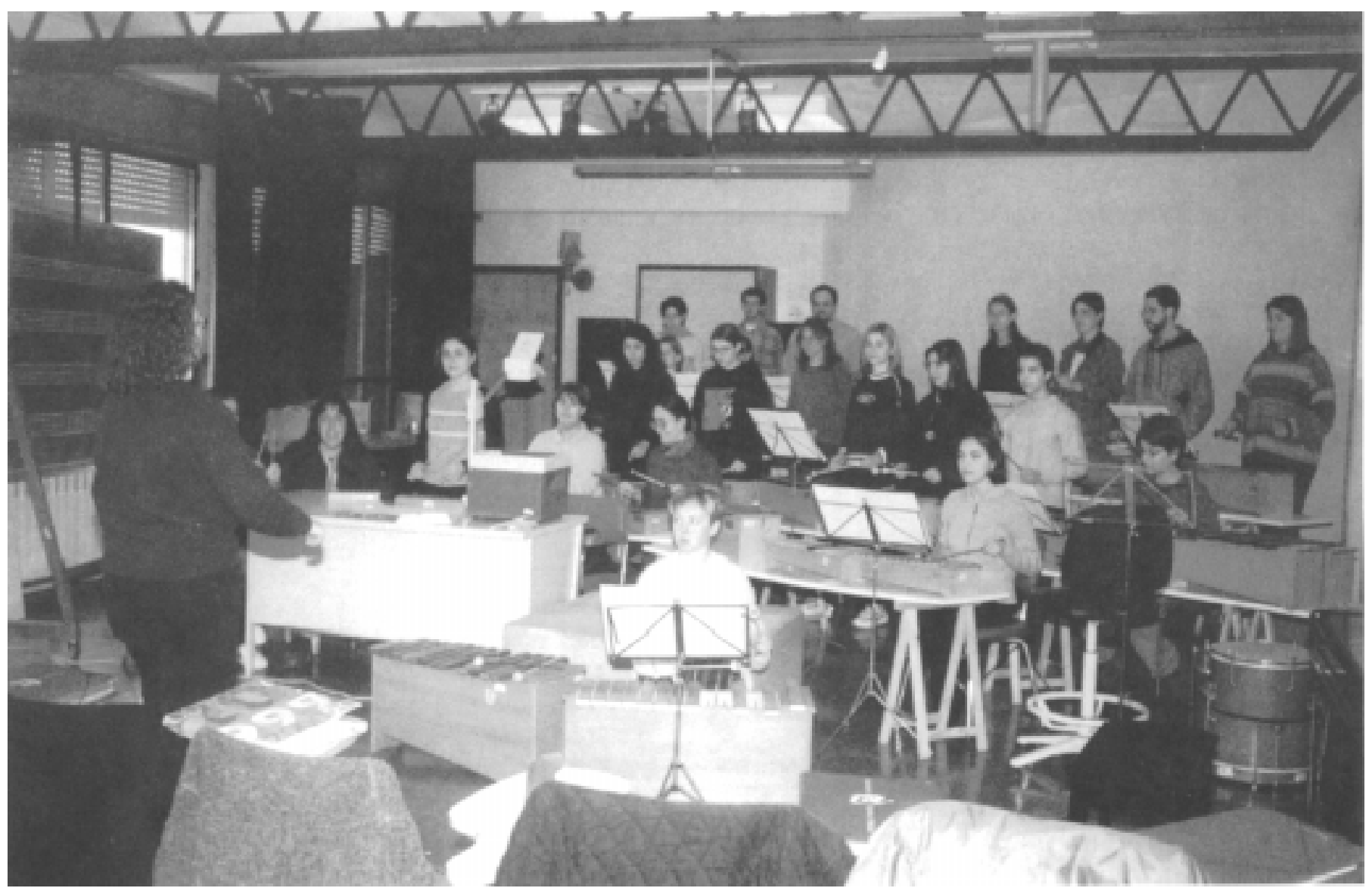

La professora Irene Jordà fent una classe de música a les instal-lacions actuals de la Facultat de Ciències de l'Educació i Psicologia 